\title{
Diet, microhabitat and time of activity in a Pristimantis (Anura, Strabomantidae) assemblage
}

\author{
Sandy B. Arroyo ${ }^{1,2}$, Víctor H. Serrano-Cardozo ${ }^{1}$ and M. Patricia Ramírez-Pinilla ${ }^{1}$ \\ ${ }^{1}$ Colección Herpetológica y Laboratorio de Biología Reproductiva de Vertebrados, Grupo de Estudios en Biodiversidad. \\ Escuela de Biología, Universidad Industrial de Santander, Bucaramanga, Colombia. E-mail: sbarroyos@unal.edu.co. \\ ${ }^{2}$ Laboratorio de Anfibios, Instituto de Ciencias Naturales, Universidad Nacional de Colombia, Bogotá, Colombia.
}

\begin{abstract}
Diet, microhabitat and time of activity in a Pristimantis (Anura, Strabomantidae) assemblage. We tested if the richness and abundance of six closely related species of Pristimantis significantly varied among three transects located at different distances from a creek in an Andean cloud forest. We found that richness and abundance of frogs varied significantly among transects, being the transect located at the forest interior the richest in frog species and number of individuals. We chose these more crowded sites to evaluate resource use differences among the species. We evaluated ecological variables such as microhabitat, diet, and time of activity in these species that are similar in morphology and body size, to determine whether they have differences in the use of these resources. Most specimens perch on leaves at heights within 1.5 and $2.0 \mathrm{~m}$ of the ground and are nocturnal; only P. douglasi was found with diurnal and nocturnal activity. The species had similar diets, they ingested a wide spectrum of prey sizes that are similar among species, months, and between transects. Almost all collected frogs were juveniles and were found during every single month of sampling suggesting continuous reproduction; however, adults and juveniles of $P$. douglasi were absent during some of the drier months, indicating seasonality. Thus, we found that most of these Pristimantis species occupy the forest interior and that there is no a strong segregation in the use of the evaluated resources, only one species had a slight difference in activity and reproductive time.
\end{abstract}

Keywords: Anura, Strabomantidae, Andean anurans, cloud forest, resource segregation.

\section{Introduction}

Within an ecological community or local assemblage, sympatric species should differ substantially in body size or in other aspects of

Received 15 February 2008.

Accepted 1 October 2008.

Distributed December 2008. morphology (Hutchinson 1959, Grant 1972). Morphological similarity among coexisting animal species sets the stage for potential interactions that may lead to competition and niche segregation (Huey and Pianka 1977). Morphologically similar species are more likely to interact than dissimilar species simply because a major portion of the behavioral and ecological activities of animals are linked with morphology (Ricklefs et al. 1981, Losos 1990). 
In an Andean cloud forest of the Cordillera Oriental of Colombia, we found an assemblage of ten species of Pristimantis ( $P$. anolirex, $P$. bicolor, P. carlossanchezi, P. douglasi, $P$. jorgevelosai, P. lutitus, $P$. merostictus, $P$. miyatai, and one undescribed species, Pristimantis sp. 1) (Arroyo et al. 2003). Six of these species are easily found ( $P$. carlossanchezi, $P$. douglasi, P. lutitus, P. merostictus, P. miyatai, and Pristimantis sp. 1), whereas the other four species are rare in this locality. Four of these species belong to the $P$. unistrigatus group (Lynch 1984), whereas P. carlossanchezi belongs to the taxonomic $P$. conspicillatus group (Arroyo 2007) and P. douglasi belongs to the P. galdi phylogentic group (Lynch 1996). The adult individuals of these six species are similar in body size and in morphology; in fact we need to do a morphometric analysis to differentiate taxonomically these species (Arroyo et al. 2005).

We evaluated the diet, microhabitat, and time of activity of these six Pristimantis species in order to determine whether these species differ in the use of these resources. Furthermore, we evaluated these resources across the sampling months to determine seasonal variation. Because nothing is known about natural history and differences in trophic and other niches in sympatric assemblages of Pristimantis, we presented these fundamental data herein.

\section{Materials and Methods}

\section{Study area}

The study was conducted at the Estación Experimental y Demostrativa El Rasgón, in the Municipality of Piedecuesta, Departamento de Santander, Colombia ( $07^{\circ} 03^{\prime} \mathrm{N}, 7^{\circ} 57^{\prime} \mathrm{W}, 2400$ $\mathrm{m}$ elevation). The area is a cloud forest reserve, located on the western flank of the northern Cordillera Oriental. Mean annual rainfall is $1645 \mathrm{~mm}$ and the mean temperature is $15.02^{\circ} \mathrm{C}$. The rainfall regime is bimodal, with one peak in
April-May and a second peak in October. November to March and July to August are the months with the lowest rainfall.

\section{Frog sampling and ecological data collection}

Frogs were surveyed by transects (Heyer et al. 1994). The use of transects is related to topography; the area has marked slopes that facilitates the use of transects preferably to quatrats. Transects can provide data of species presence/absence, richness, relative abundance, and density (number of individuals/area surveyed). We established three different transects of $100 \times 2 \mathrm{~m}$. One transect was located in the forest interior ( $200 \mathrm{~m}$ from the next creek and forest edge, Interior Forest Transect); the second was located in a creek (Creek Transect), and the third transect was parallel to it, $20 \mathrm{~m}$ above the creek (Parallel Creek Transect). These three sites have differences in the vegetation and were surveyed and samples were collected no more than once per day to avoid excessive disturbance. We collected in $7 \mathrm{mo}$ (from March 1999 to March 2000; see months in Figure 1B). We visited the locality for one week each one of the sampled months. During this week, all the three transects were sampled. The specimens were collected by hand and kept in individually labelled bags. Because, frogs are capable of digesting their prey rapidly (Vitt and Caldwell 1994), the frogs were killed within $3 \mathrm{~h}$ of the capture. Individuals were fixed in $10 \%$ formalin, preserved in $70 \%$ ethanol and are housed in the herpetological collection of the Museo de Historia Natural, Escuela de Biología, Universidad Industrial de Santander, Colombia (UIS-A). This scientific herpetological collection is registered by the Ministerio del Ambiente of the Colombian government.

We employed a G-test to assess whether species richness of Pristimantis varied among transects using the data of all sampling months together. For the most abundant species we put together the abundance data of the transects to 
detect a significant variation among the months of sampling using a Serial run test. We also checked whether the abundance of the most abundant species significantly changed between seasons (rainy and drier months) using a G-test.

\section{Microhabitat use and time of activity}

Habitat use data such as perch height (measured with a metric tape) and substrate type (leaf litter, branch, leaf, stone, and trunks) were recorded for each sampled frog. We performed a Kruskal-Wallis nonparametric test in order to detect perch height preferences among Pristimantis species in each sampled transect. For the most abundant species we put together the perch height data of the two transects to test whether perch height varied for each species among sampling months. Also, for the common species we used Spearman correlation to test the effect of body size on perch height.

Activity time was measured sampling each transect in the morning (from 9:00 $\mathrm{h}$ to $11: 00$ $\mathrm{h}$ ), in the afternoon (from 15:00 h to 17:00 h) and in the night (from 18:00 h to 22:00 h) during different days to avoid continuous disturbance.

\section{Diet}

Dietary studies have demonstrated that postmetamorphic frogs change both prey type and prey size as they grow (Donnelly 1991, Lima and Magnusson 1998). Because juvenile and adult Pristimantis occur in the same microhabitats and forage at the same place (leaf litter and on the bushes [J. D. Lynch, pers. comm. and pers. obs.]), we analyzed the diet for both juveniles and adults combined. Stomachs of frogs were removed and dissected, and prey items were sorted in a Petri dish. Prey items were counted and their lengths measured to an accuracy of $0.02 \mathrm{~mm}$ with either dial calipers or micrometer on a microscope, depending on prey size. Prey items were classified and identified to order taxonomic level. We did not use individual volumes because some prey were disarticulated or were so small that we could not measure them accurately.

Kruskal-Wallis nonparametric test was used to compare sizes of prey ingested among Pristimantis species. Species of the two transects together with at least five items in their stomachs were included in the analysis of prey size. We tested whether the lengths of the most frequently consumed items by species were similar among species by means of a KruskalWallis nonparametric test. To test for the effect of body size on prey size, we used Spearman correlation for the most common species.

\section{Other ecological data}

For each specimen, we measured snout-vent length (SVL) and mouth width with Vernier callipers $( \pm 0.02 \mathrm{~mm})$. We used a KruskalWallis nonparametric test to determine whether members of the Pristimantis assemblage are similar in body size. We dissected and preserved the reproductive and digestive tracts. The condition of the oviduct and ovary was recorded as oviduct width (at midlength, measured with an ocular micrometer) and the number of large-yolked follicles in the ovaries. For males, left testis length was measured with an ocular micrometer and the convolution of the deferent ducts was observed. Based on the anterior data of the macroscopic observation of the gonads and ducts we determined age structure and reproductive condition. Individuals were assigned to one of three age-sex groups (adult female, adult male, and juveniles). Adult females were considered those females with yolked follicles and females with non yolked follicles but with distended oviducts, and adult males those individuals with large testes and convoluted deferent ducts. We classified the adult females as previtellogenic (ovaries without yolked follicles) and vitellogenic (ovaries containing vitellogenic follicles and convoluted oviducts). The reproductive stage determined for each specimen allowed us 
to establish the reproductive activity for males and females in each month and during the whole sampling time, as well as the minimum size of sexual maturity for females of each population. The minimum size at sexual maturity was determined by the body size (SVL) of the smallest female with yolked follicles.

\section{Results}

Pristimantis assemblage and species abundance

Of the three transects, The Forest Interior Transect had the most species and individuals (Figure 1A). All six species of Pristimantis studied were found in this transect. The Creek Parallel Transect had fewer species and individuals, and the transect on the creek had the lowest number of species and individuals; during the year of sampling only one P. carlossanchezi was collected on this transect (Figure 1A). For this reason, we did not consider this transect in the ecological analyses. Then, the species richness of Pristimantis varied significantly among transects $\left(G_{0.05,2}=6.26, P<0.05\right)$.

On the Interior Forest Transect, $P$. miyatai was the most abundant species; this species represented $42.8 \%$ of the total abundance and therefore is the most common species in this study, followed by P. douglasi with $16.3 \%$ of the total abundance.

On the Parallel Creek Transect, P. merostictus was the most abundant species and was the third most abundant in this study with 12.8 $\%$ of the total abundance. P. lutitus, Pristimantis sp. 1 and $P$. carlossanchezi were the rarest, with a percent abundance lower than $5.0 \%$.

We included only the three most abundant species ( $P$. miyatai, $P$. douglasi and P. merostictus) in the analysis of seasonal variation. For these three species, we put together the abundance data for the two transects (Interior Forest Transect and Parallel Creek Transect). The relative abundance of these three most common species was not different between dry and rainy seasons $\left(G_{0.05,1,2}=12.1 P>0.25\right)$. The resulting seasonal comparison demonstrates that Pristimantis miyatai and $P$. merostictus did not vary significantly in abundance during the year $\left(C_{0.05,2,2}=3.4, P=0.8\right.$ and $C_{0.05,2,2}=3.4, P=$ 0.2 ), whereas $P$. douglasi showed significant differences in the number of individuals among the months of sampling (serial run test $-C_{0.05,1,1}=$ $5, P=0.02$ ) (Figure 1B).

\section{Microhabitat and time of activity}

Frogs of all observed species of Pristimantis were found on vegetation within $0-2.0 \mathrm{~m}$ of the ground. Heights between 1.5 and $2.0 \mathrm{~m}$ were most frequently observed $(74.6 \%$, Figure $2 \mathrm{~A})$. Leaves were the preferred $(88.6 \%)$ perch site among the frogs.

Kruskal-Wallis test results showed that there was no significant difference in the use of perch height among species on The Interior Forest Transect and on Parallel Creek Transect respectively $\left(H_{5,97}=7.49, P=0.1864 ; H_{2,26}=\right.$ $1.22, P=0.543)$. For $P$. miyatai, $P$. douglasi and $P$. merostictus, no monthly variation was observed in the use of this spatial resource $\left(H_{1,20}\right.$ $=0.91, P=0.33$ ) and none of these three most common species showed correlation between body size and vertical position $(P$. miyatai, $R=$ $0.024, P<0.85, n=60 ; P$. douglasi, $R=0.031$, $P<0.88, n=24 ;$ P. merostictus, $R=0.485, P<$ $0.09, n=16$ ).

Most individuals were active beginning at about 18:30 h. A few individuals were collected during the day $(6.5 \%$, Figure $2 \mathrm{~B})$; these were juvenile $P$. miyatai moving around in leaf litter, and few calling males $P$. douglasi perched on vegetation.

\section{Diet}

Diet data for this study are based on 123 stomachs from the six studied species of Pristimantis. One hundred and fifty prey items belonging to 17 prey categories were identified to the level of order in insects and to higher 

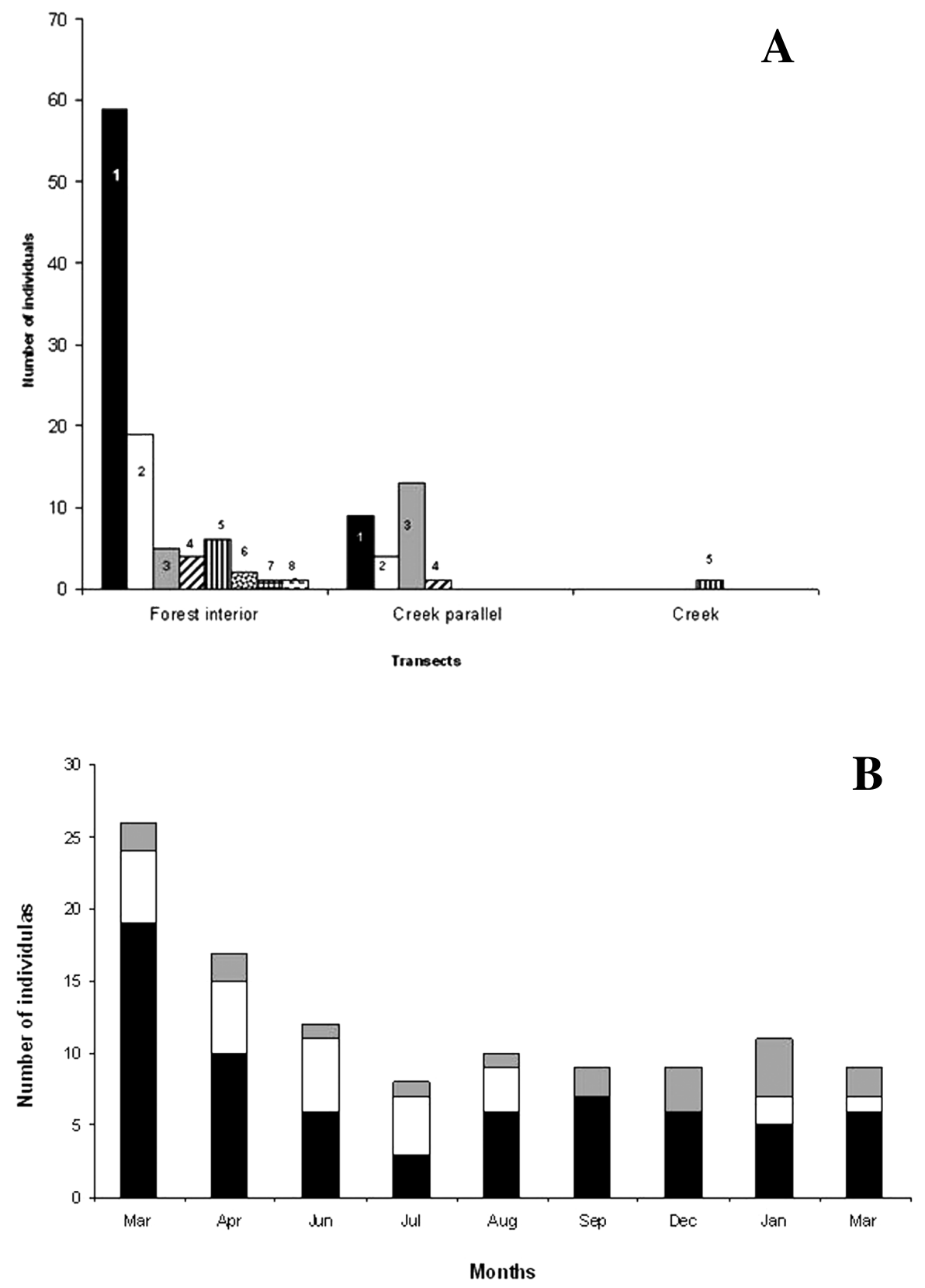

Figure 1 - (A) Distribution of Pristimantis species at El Rasgón in the three transects sampled. The number of species drops with transition from forest interior to aquatic habitat. (B) Pristimantis douglasi (in white) showed significant differences in the relative abundance of individuals collected during the months of sampling, individuals were not observed from September to December whereas $P$. miyatai (in black) and P. merostictus (in gray) were observed during the year of sampling from March 1999 to march 2000. (1) Pristimantis miyatai, (2) P. douglasi, (3) P. merostictus, (4) P. lutitus, (5) P. carlossanchezi, (6) Pristimantis sp. 1, (7) P. anolirex, (8) P. prolixodiscus. 
taxonomic levels in other arthropod prey item groups (Table 1). The taxonomic orders with the highest frequency of occurrence (percentage of stomachs containing each prey type) were Collembola, Coleoptera, Isopoda, and Araneae, and these preys items were found in the stomachs of the three most common species. Spiders and coleopterans were the most abundant prey items consumed by individuals of P. miyatai. Also, collembolans are an important item in $P$. miyatai, whereas isopods seem to be commonly consumed by both $P$. miyatai and $P$. douglasi (Table 1).

Coleopterans were observed in stomach contents of all species, except for P. lutitus. However, the sample of stomach contents for this species was small. Individuals of Pristimantis sp. 1 also contained few prey items in their stomachs. Hence, we did not consider the diet of P. lutitus or Pristimantis sp. 1 in the prey size analysis. Then, species included in the analysis of prey size were $P$. miyatai, $P$. douglasi, $P$. merostictus and $P$. carlossanchezi.

The comparison of prey size among species of Pristimantis reveals that frogs collected along the Forest Interior Transect differ significantly in the size of the prey that they eat $\left(H_{3,116}=18.3, P=0.0162\right)$ (Figure 3A). In contrast, no significant differences were observed in prey size consumed by species observed on the Creek Parallel Transect $(P$. douglasi, $P$. miyatai and $P$. merostictus $)\left(H_{2,37}=\right.$ $0.52, P=0.5869)$. We tested whether the lengths of the two most frequently consumed items (Coleoptera and Araneae) by species collected at the Forest Interior Transect were similar among species. Pristimantis douglasi and $P$. carlossanchezi eat significantly differently sized Araneae (Figure 3B), whereas the Coleoptera consumed by $P$. miyatai, $P$. douglasi and $P$. merostictus are not significantly different in length $\left(H_{2}{ }_{23}=4.72, P=0.0941\right)$. Only $P$. miyatai shows a significant correlation between prey size and jaw width $(R=0.1071$, $P<0.002)$. In Pristimantis douglasi and $P$. merostictus, mouth size and prey length are uncorrelated $(R=0.0005, P<0.889$, $R=0.0687, P<0.264$, respectively).

\section{Other ecological data}

Almost all captured individuals of $P$. miyatai, $P$. merostictus, $P$. lutitus, and Pristimantis sp 1 and. P. carlossanchezi were juveniles (less than $17 \mathrm{~mm}$; Lynch, 1984) and were observed every sampling month. Adult individuals of the six species have similar body sizes $\left(H_{4,66}=9.38, P=0.052\right)$.

Pristimantis douglasi was not found or heard at the beginning of the dry season. Reproductive activity in $P$. douglasi was evident from the male calling activity and from the observation of vitellogenic follicles in females. Some yolked follicles were also observed in females of $P$. miyatai, but calling activity was never heard in $P$. miyatai, $P$. lutitus, $P$. merostictus, $P$. carlossanchezi and Pristimantis sp. 1 males. Sexually mature females had enlarged and convoluted oviducts or large yellow-orange ovarian follicles. The minimum size at sexual maturity is $24.72 \mathrm{~mm}$ SVL for $P$. miyatai females (adult females range from 24.72- $27.19 \mathrm{~mm} \mathrm{SVL}$ ), and 23.03 for $P$. douglasi females (range 23.02-26.08 mm). Reproductive females of $P$. miyatai were observed during the months of March, July, August, and October; whereas reproductive females of $P$. douglasi were found only during the first months of the year.

\section{Discussion}

Species richness and abundance vary significantly among the three transects. The abundance of species among transects seems to depend on the distance to the nearest body of water; the number of species in vegetation over the aquatic habitats is lower than in the forest interior. The Pristimantis assemblage at El Rasgón is not tied to aquatic environments. This result is in accordance with the reproductive 

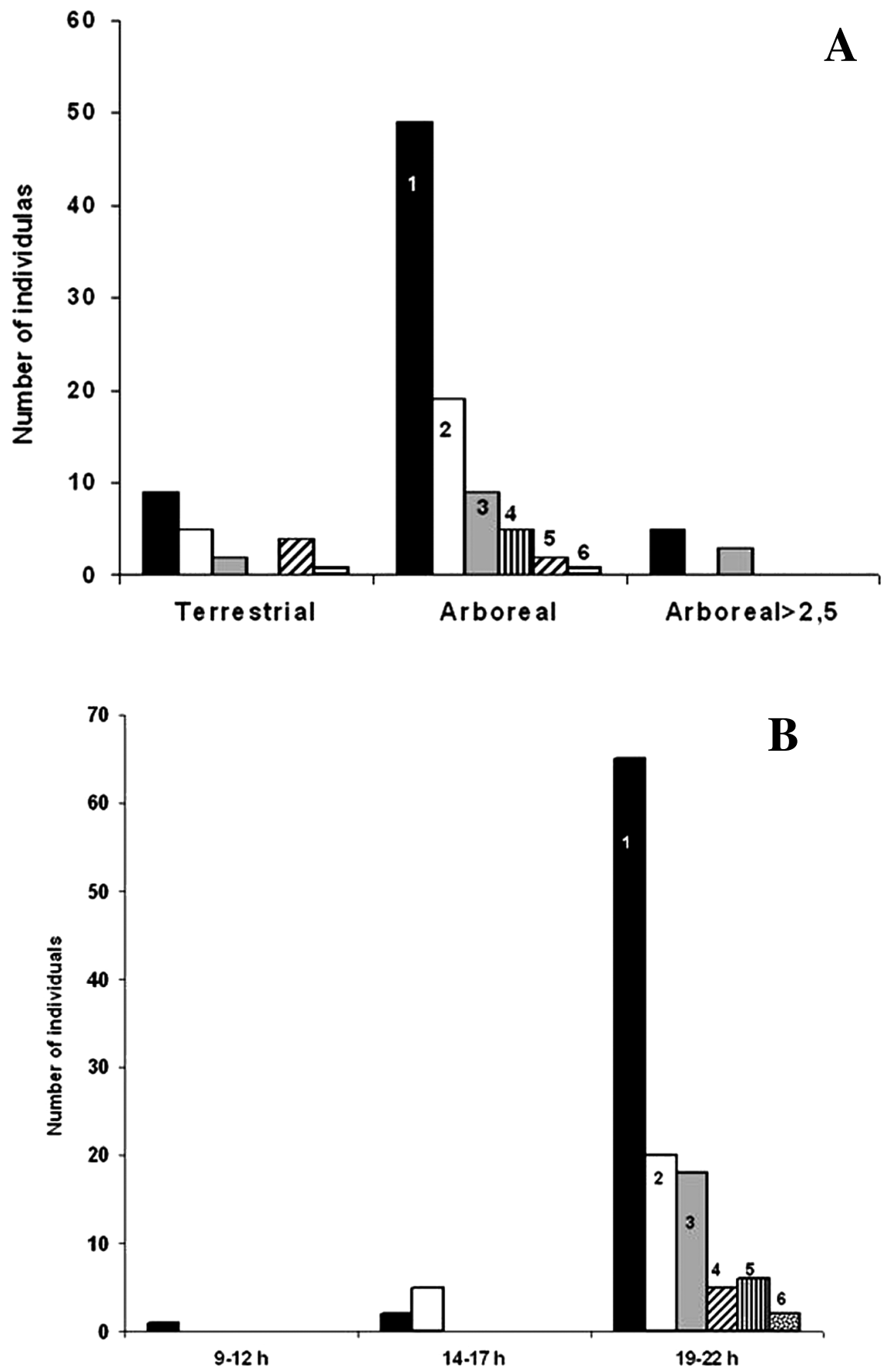

Figure 2 - (A) Microhabitat use in Pristimantis assemblage. (B) Time of activity. The majority of individuals were observed at heights within $1.5 \mathrm{~m}$ of the ground and showed nocturnal activity. (1) Pristimantis miyatai, (2) P. douglasi, (3) P. merostictus, (4) P. lutitus, (5) P. carlossanchezi, (6) Pristimantis sp. 1. 
Arroyo et al.

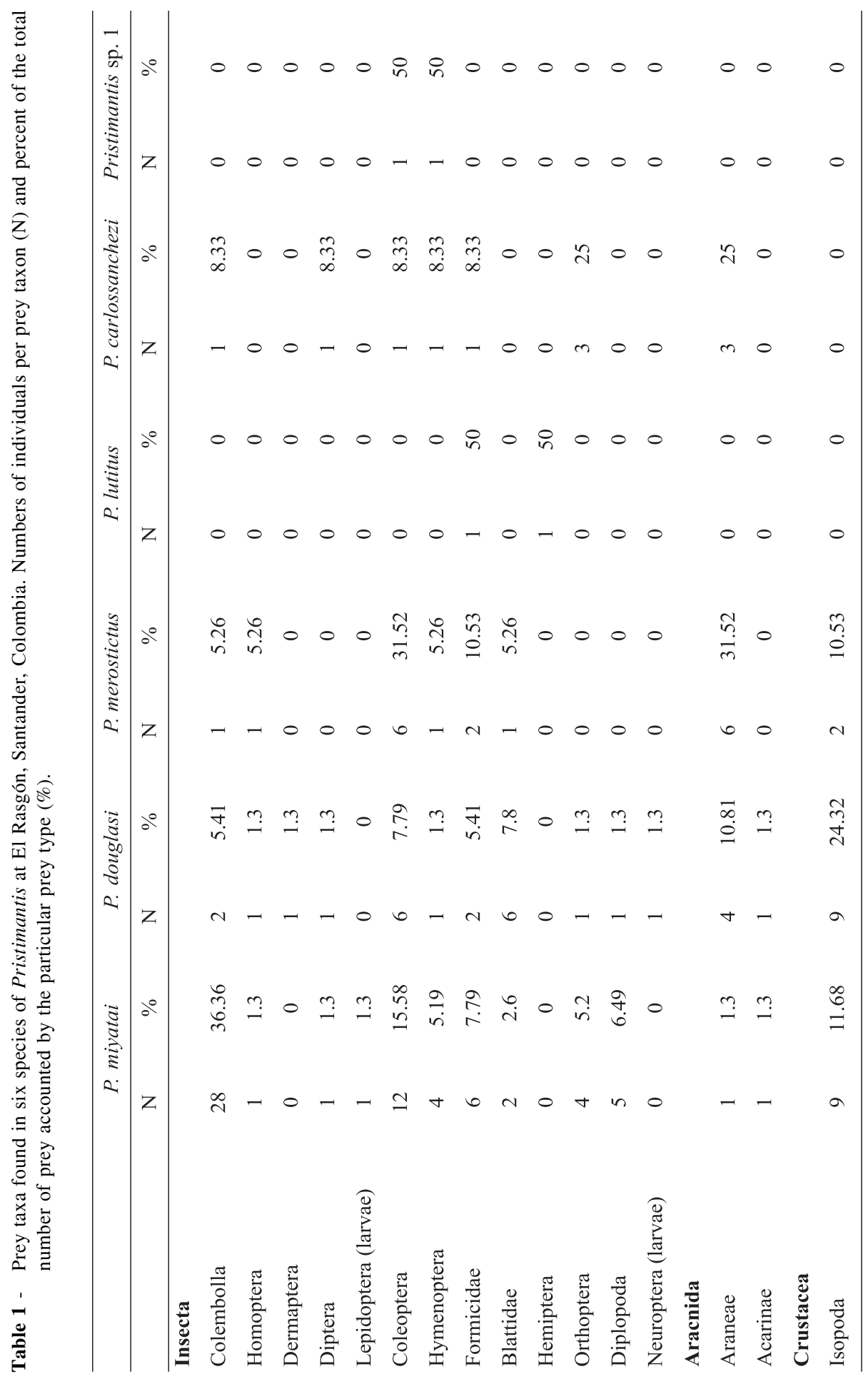



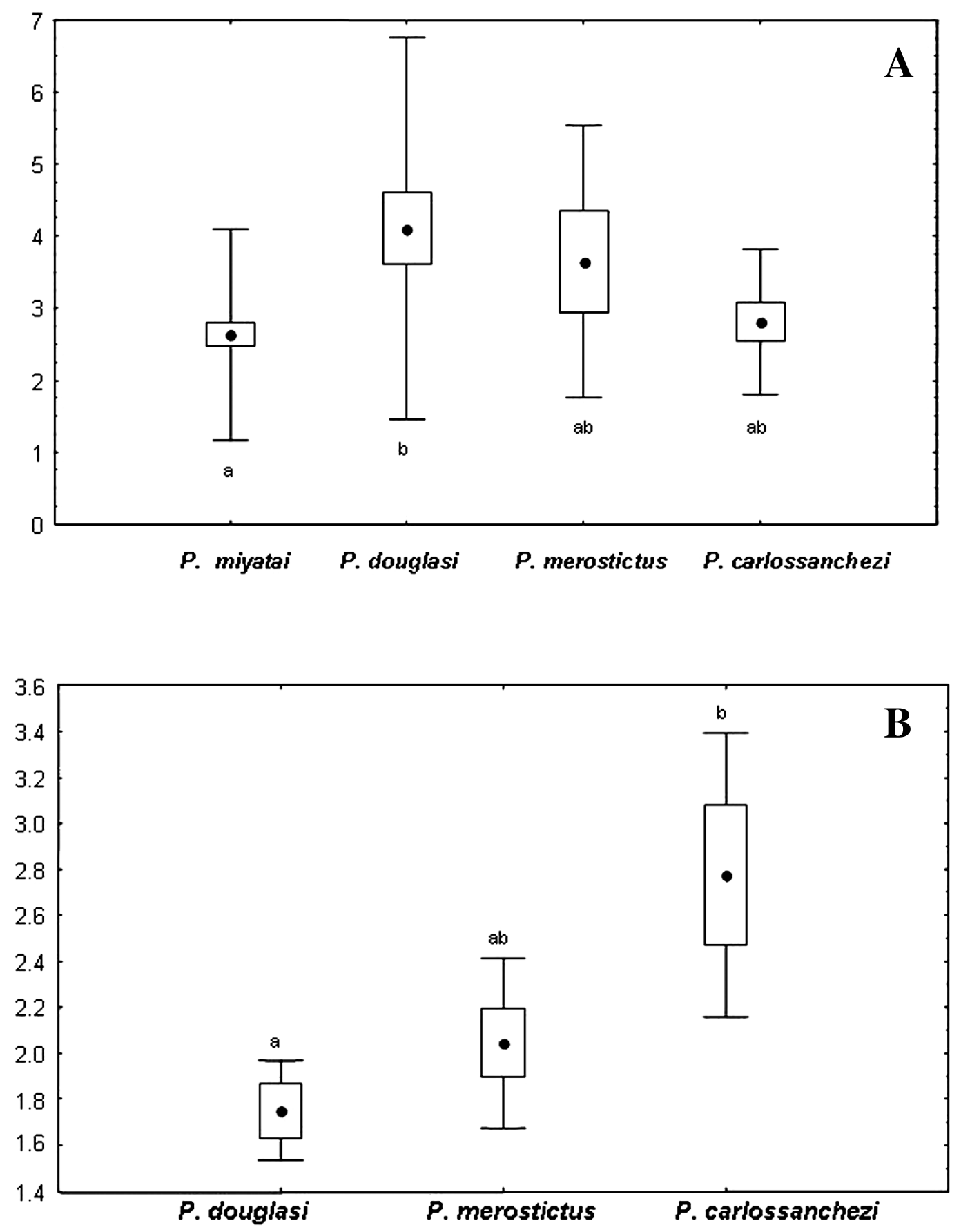

Figure 3 - Length of ingested prey $(\mathrm{mm})$ by Pristimantis species. (A) Species of Forest Interior Transect showed significant differences in prey size. (B) There were significant differences in the prey size of Araneae. Different superscripts indicate significant differences. point $=$ Mean box $=$ Standard Error whiskers $=$ Standard Deviation . 
mode of Pristimantis, direct development, in which females deposit terrestrial eggs that hatch directly into miniature adults (Townsend and Stewart 1985, Woolbright 1985).

The species of Pristimantis studied does not differ in the space they occupy. Most species of Pristimantis were observed perched on leaves at heights below $210 \mathrm{~cm}$. Our results about microhabitat use are consistent with other Pristimantis assemblage studies that show use of vertical position at heights within $150 \mathrm{~cm}$ of the ground (Miyamoto 1982, Lynch and Duellman 1997, Höbel 1999). Furthermore, we found that perch site use is not influenced by seasonal changes. Because most individuals are active beginning at about $18: 30 \mathrm{~h}$, we think that the Pristimantis assemblage at El Rasgón is arboreal/nocturnal in the use of microhabitat and time of activity, although one species, $P$. douglasi is characterized as arboreal with diurnal and nocturnal activity. We think that the number of $P$. douglasi males collected could be more, we heard a lot of $P$. douglasi calling males but they were hard to collect because calling sites were often too difficult to access.

In Pristimantis miyatai, there is a significant correlation between prey size and mouth size, suggesting that size of consumer determines prey size; however, this species did not show significant differences in prey size. Generally in anurans, there is a positive correlation between body size and prey size (Toft 1980, 1981, 1985, Lima 1998, Parmalee 1999), but this generalization has limited application to frogs that are dietary generalists (Lynch and Duellman 1997). The generalization about body size and prey size applies to maximum-size prey that can be captured and ingested, but generalist frogs do not forage only at maximum prey size (Lynch and Duellman 1997). Our results in P. miyatai are consistent with the argument of Lynch and Duellman (1997). Moreover, we conclude that species of Pristimantis at El Rasgón select their prey according to their abundance because we did not observe differences in prey ingested within species between transects. This result is not unexpected because most species of Pristimantis are characterized as dietary generalists. Members of Pristimantis and Eleutherodactylus have been characterized as insectivorous generalists that choose prey depending on food availability (Ovaska 1991, Lynch and Duellman 1997, Woolbright and Stewart 1997). Species of Pristimantis in this study ingested a wide spectrum of prey sizes and types.

We also observed a slight segregation by individuals of $P$. douglasi during the mating season. P. douglasi seems to show more seasonality in its reproduction than the other species of Pristimantis studied. We did not find or hear individuals of $P$. douglasi at the beginning of the dry season, and most of the adult males were heard and observed in the rainy season. In contrast, the populations of $P$. miyatai, P. merostictus, P. lutitus, Pristimantis sp. 1 and $P$. carlossanchezi consisted of individuals of small body size during all months of sampling.

In summary, we did not find strong differences in the use of the diet, microhabitat and time of activity among the six species of Pristimatis at El Rasgón, just a slight segregation was observed by $P$. douglasi individuals in activity time and reproductive time.

\section{Acknowledgements}

We are indebted to John Lynch who identified the Pristimantis and suggested several important ideas to us. Also, we thank J. Caicedo, L. Cortes, Y. Granados, A. Jerez, P, Martínez, L. Navarro, J. Ortega, H. Súarez for their help with fieldwork. We also appreciate the help from Daniel R. Miranda for providing valuable suggestions that greatly contributed to improvements of earlier versions of this paper. J. P. Ramírez helped in the edition of the final version. This study was consistent with government guidelines on the ethical treatment of animals and all applicable regulations; also, it was done with permits from the Corporación 
Autónoma de la Meseta de Bucaramanga (CDMB). Partial financial support was provided by Dirección de Investigaciones de la Facultad de Ciencias de la Universidad Industrial de Santander. L. Trueb, W. Duellman and the Editors made useful and valuable suggestions on the manuscript.

\section{References}

Arroyo, S. B. 2007. New frog (Brachycephalidae: Eleutherodactylus) from the Western Flank of the Cordillera Oriental of Colombia. Zootaxa 1389: 61-68.

Arroyo, S. B., A. Jerez and M. P. Ramirez-Pinilla. 2003. Anuros de un bosque de niebla de la Cordillera Oriental de Colombia. Caldasia 25: 153-157.

Arroyo, S. B., P. M. Sánchez, M. P. Ramírez-Pinilla, H. Suárez, and D. R. Miranda-Esquivel. 2005. Morphometric analysis to differentiate taxonomically seven species of Eleutherodactylus (Amphibia: Anura: Leptodactylidae) from an Andean cloud forest of Colombia. Zootaxa 1018: 1-14.

Donnelly, M. A. 1991. Feeding patterns of the strawberry poison frog, Dendrobates pumilio (Anura:Dendrobatidae). Copeia 1991: 723-730.

Grant, P. R. 1972. Convergent and divergent character displacement. Biological Journal of the Linnean Society 4: 39-68.

Heyer, W. R., R. W. Donnelly, L.A. McDiarmid, and M. S. Foster (eds.). 1994. Measuring and Monitoring Biological Diversity - standard methods for amphibians. Smithsonian Institution Press, Washington, D. C. 388 pp.

Höbel, G. 1999. Notes on the natural history and habitat use of Eleutherodactylus fitzingeri (Anura: Leptodactylidae). Amphibia-Reptilia 20: 65-72.

Huey, R. B and E. R. Pianka. 1977. Patterns of niche overlap among broadly sympatric versus narrowly sympatric Kalahari lizards (Scincidae: Mabouya). Ecology 58: 119-128.

Hutchinson, G. E. 1959. Homage to Santa Rosalia, or why are there so many kinds of animals? American Naturalist 93: 245-249

Lima, A. P. 1998. The effects of size on the diets of six sympatric species of postmetamorphic litter anurans in Central Amazonia. Journal of Herpetology 32: 392 399.

Lima, A. P and W. E Magnusson. 1998. Partitioning seasonal time: interactions among size, foraging activity and diet in leaf-litter frogs. Oecologia 116: 259-266.

Losos, J. B. 1990. The evolution of form and function: morphology and locomotor performance in West Indians Anolis lizards. Evolution 44: 1189-1203.

Lynch, J. D. 1984. New frogs (Leptodactylidae: Eleutherodactylus) from cloud forest of the northen Cordillera Oriental. Colombia. Milwaukee Public Museum Contributions in Biology and Geology 60: 1-19.

Lynch, J. D. 1996. New frog (Eleutherodactylus: Leptodactylidae) from the Andes of eastern Colombia, part of a remarkable pattern of distribution. Copeia 1996: 103-108.

Lynch, J. D and W. E. Duellman. 1997. Frogs of the genus Eleutherodactylus (Leptodactylidae) in western Ecuador: systematycs, ecology and biogeography. The University of Kansas. Natural History Museum. Special Publications 23: 1-236.

Miyamoto, M. M. 1982. Vertical use by Eleutherodactylus frogs (Leptodactylidae) at two Costa Rican localities. Biotropica 14: 141-144.

Ovaska, K. 1991. Reproductive phenology, population structure, and habitat use of the frog Eleutherodactylus johnstonei in Barbados, West Indies. Journal of Herpetology 25: 424-430.

Parmalee, J. R. 1999. Trophic ecology of a tropical anuran assemblage. Scientific Papers, Natural History Museum, The University of Kansas 11: 1-59.

Ricklefs R., E. D. Cochran and E. R Pianka. 1981. A morphological analysis of the structure of communities of lizards in desert habitats. Ecology 62: 1474-1483.

Toft, C. A. 1980. Feeding ecology of thirteen syntopic species of anurans in a seasonal tropical environment. Oecologia 45: 131-141

Toft, C. A. 1981. Feeding ecology of Panamanian litter anurans: patterns in diet and foraging mode. Journal of Herpetology 15: 139-144.

Toft, C. A. 1985. Resource partitioning in amphibians and reptiles. Copeia 1985: 1-20.

Townsend, D. S and M. M, Stewart. 1985. Direct development in Eleutherodactylus coqui (Anura: Leptodactylidae): a staging table. Copeia 1985: 423-36.

Vitt, L. J and J. P Caldwell. 1994. Resource utilization and guild structure of small invertebrates in the Amazon forest leaf litter. Journal of Zoology 234: 463-476.

Woolbright, L. L. 1985. Patterns of nocturnal movement and calling by the tropical frog Eleutherodactylus coqui. Herpetologica 41: 1-9.

Woolbright, L. L. and M. M Stewart. 1997. Foraging success of the tropical frog Eleutherodactylus coqui: the cost of calling. Copeia 1997: 69-75. 